Aporte Santiaguino 11(2), julio-diciembre 2018: 199-210

ISSN-L 2616-9541

\title{
Inducción de embriogénesis somática en Perezia coerulescens Wedd, planta medicinal altoandina
}

Induction of somatic embryogenesis in Perezia coerulescens Wedd, medicinal plant highland

Percy Olivera-Gonzales ${ }^{1}$, Carmen Tamariz-Angeles ${ }^{1}$ y Edwin Vega-Portalatino ${ }^{1}$

\section{RESUMEN}

Perezia coerulescens, una especie nativa peruana, es usada para los "nervios" en medicina tradicional y considerada en estado vulnerable debido a su extracción masiva para su comercialización. En este sentido, el objetivo de la investigación fue obtener embriones somáticos como alternativa de su multiplicación. Las hojas, raíces, rizomas, brotes pequeños $(15-20 \mathrm{~mm})$ y brotes grandes $(25-30 \mathrm{~mm})$ provenientes de plantas cultivadas in vitro fueron cultivadas en $\mathrm{MS}^{1} / 2$ con sacarosa $(2 \%)$ y agar-agar $(0,75 \%), 16$ horas luz a $16-20{ }^{\circ} \mathrm{C}$, suplementado con ANA (2 mg/L) o 2,4-D (0,2; 1 y $\left.2 \mathrm{mg} / \mathrm{L}\right)$ y un control sin hormona. Se encontró que ANA $(2 \mathrm{mg} / \mathrm{L})$ y 2,4-D $(2 \mathrm{mg} / \mathrm{L})$ a los dos meses indujeron la formación de callos al 100\% en los brotes pequeños y grandes, del mismo modo 2,4-D (1 mg/L) indujo callogénesis al 100\% en los brotes pequeños y grandes a los cuatro meses. Sin embargo, los callos embriogénicos provenientes del tratamiento 2,4-D (2 mg/L) se fenolizaron a los cuatro meses. Considerando el tamaño de callo y número de embriones germinados el mejor tratamiento para la formación de embriones somáticos fue ANA (2 mg/L) a cuatro meses de exposición en los brotes pequeños.

Palabras clave: cultivo in vitro; callo embriogénico; reguladores de crecimiento.

\footnotetext{
1 Universidad Nacional Santiago Antúnez de Mayolo. Huaraz, Perú.

(C) Los autores. Este artículo es publicado por la Revista Aporte Santiaguino de la Universidad Nacional Santiago Antúnez de Mayolo. Este es un artículo de acceso abierto, distribuido bajo los términos de la Licencia Creative Commons Atribución-NoComercial-CompartirIgual 4.0 Internacional. (http://creativecommons.org/licenses/ by-nc-sa/4.0/), que permite el uso no comercial, distribución y reproducción en cualquier medio, siempre que la obra original sea debidamente citada.
} 


\begin{abstract}
Perezia coerulescens, a native peruvian species, is used as tranquilizer in folk medicine and considered vulnerable status due extensive collection for its commercialization. Then, the aim of this research was obtain somatic embryos as alternative for its multiplication. Leaves, roots, rhyzomes, small shoot $(15-20 \mathrm{~mm})$ and big shoot $(25-30 \mathrm{~mm})$ from plants culture in vitro were grown using $\mathrm{MS}^{1} / 2$ culture medium with sucrose $(2 \%)$, agaragar $(0,75 \%), 16$ hours of light, $16-20{ }^{\circ} \mathrm{C}$, supplemented with NAA (2 mg/L), 2, 4-D (0,2; 1 and $2 \mathrm{mg} / \mathrm{L})$ and without hormone. It was found that NAA $(2 \mathrm{mg} / \mathrm{L})$ and 2, 4-D (2 mg/L) induced callogenesis in 100\% of small shoot and big shoot at two months, likewise 2, 4-D (1 mg/L) induced 100\% of callogenesis of small shoot and big shoot at four months. However, embryogenic callus 2, 4-D (2 mg/L) treatment was fenolized at four month. Considering callus size and number of germinated somatic embryos, the best treatment to embryonics somatic was NAA $(2 \mathrm{mg} / \mathrm{L})$ at four moth of culture and using small explants.
\end{abstract}

Keywords: In vitro culture; callus; growth regulators.

\title{
INTRODUCCIÓN
}

La embriogénesis somática representa una importante herramienta de cultivo de tejidos in vitro usada para la regeneración, multiplicación y propagación a gran escala de genotipos de interés (Celestino et al., 2005; Silveira et al., 2013); así mismo en la actualidad permite la producción de plantas transgénicas y en la conservación clonal de alta productividad (Celestino et al., 2005). En esta técnica, una célula o pequeño número de células somáticas forman un embrión somático (Silveira et al., 2013) mediante dos procesos: (i) la dediferenciación celular con la formación de callos o suspensiones celulares, y es conocido como embriogénesis somática indirecta, o (ii) dediferenciación sin formación de callos, por lo que se denomina embriogénesis somática directa (Von Arnold, 2008). En ambos casos, las células revierten su estado de diferenciación, y adquieren pluripotencialidad y un nuevo programa de desarrollo gracias a la participación y regulación de hormonas vegetales que se relacionan con las vías que controlan los procesos de remodelación de la cromatina, cambios en el patrón de expresión génica, reactivación del ciclo de división celular, y regulación y modificación de la síntesis proteica (Thomas y Jiménez, 2005). Estas hormonas son las auxinas y citoquininas (Vieira et al., 2010), donde las auxinas pueden inducir la formación de células embriogénicas y promover la división celular repetitiva (Taiz y Zeiger, 2010); mientras que las citoquininas son necesarias para la inducción de la embriogénesis en muchas especies de dicotiledóneas (Abdi y Hedayat, 2011).

En nuestro país los trabajos en esta materia son escasos y más aún cuando se trata de 
plantas medicinales nativas altoandinas. Sin embargo existe información de trabajos realizados en otros países, tal es así que Rodríguez et al. (2015) realizaron la regeneración de plantas de plátano FHIA-25 mediante embriogénesis somática a partir de ápices meristemáticos; Kumar et al. (2016) realizaron inducción de callos, embriogénesis somática y regeneración de plantas en especies de Crocus; Shekhawat y Manokari (2016) reportaron la generación de plantas de Hybanthus enneaspermus mediante embriogénesis somática; Peddaboina et al. (2016) realizaron la embriogénesis somática y la regeneración de plantas de Capsicum baccatum L.; Brunetti et al. (2007) realizaron la micropropagación de "Tomillo de las sierras" Hedeoma multiflorum Benth; Ortíz et al. (2007) reportan la regeneración in vitro de plantas de poleo (Lippidia turbinata Griseb var turbinata); entre otros.

En este sentido, frente a que Perezia coerulescens es una especie vegetal medicinal nativa en situación vulnerable (El Peruano, 2006) porque se colecta en grandes cantidades para su comercialización en las ferias populares, la presente investigación tuvo como objetivo inducir la formación de embriones somáticos en Perezia coerulescens, usando varios órganos y reguladores de crecimiento vegetal; a fin de obtener una alternativa para su propagación y conservación.

\section{MATERIALES Y MÉTODOS}

\section{Material biológico}

Los tejidos u órganos de Perezia coerulescens se obtuvieron de plántulas mantenidas en cultivo in vitro del Laboratorio de Biología de la Facultad de Ciencias de la Universidad Nacional Santiago Antúnez de Mayolo - Huaraz.

\section{Explantes}

Se utilizaron varios tipos de explantes: brotes grandes de 25-30 mm de longitud, brotes pequeños de 10 - $20 \mathrm{~mm}$ de longitud aprox.; hojas de $25 \mathrm{~mm}$ de longitud aprox.; raíces de $20 \mathrm{~mm}$ aprox. y rizomas de $20 \mathrm{~mm}$ aprox.

\section{Medios de cultivo}

Los cultivos fueron mantenidos en Murashige y Skoog (1962) a mitad de sales (MS1/2), suplementado con sacarosa 2\% y agar - agar 0,7\%. El pH se ajustó a 5,67.

\section{Inducción de embriones somáticos}

Para inducir la formación de callos se realizaron los siguientes tratamientos: ANA a 2 $\mathrm{mg} / \mathrm{L}, 2,4-\mathrm{D}$ a 0,$2 ; 1,0 ; 2,0 \mathrm{mg} / \mathrm{L}$, y un testigo sin regulador de crecimiento.

Por cada medio de inducción se sembraron 20 explantes en frascos de vidrio conteniendo $25 \mathrm{~mL}$ de medio de cultivo. Todos los tratamientos tuvieron las mismas condiciones 
de iluminación (16 horas x día) y temperatura ambiental $\left(16-20^{\circ} \mathrm{C}\right)$. Las evaluaciones se realizaron mensualmente, considerando el tamaño del callo y germinación de embriones; además se observaron las diversas etapas de la formación de embriones con ayuda de un microscopio estereoscópico.

\section{Análisis estadísticos}

Se usó el Diseño Completamente al Azar (DCA), se calcularon las medias y las desviaciones estándar por tratamiento. También se aplicó el análisis de varianza ANOVA y la prueba de comparación de medias de Duncan con un nivel de significancia $p<0,05$.

\section{RESULTADOS}

\section{Formación de callos (callogénesis)}

De acuerdo a la figura 1, se observa que todos los brotes pequeños y grandes cultivados en $2 \mathrm{mg} / \mathrm{L}$ ANA y $2 \mathrm{mg} / \mathrm{L} 2$, 4-D formaron de callos a partir de los dos meses de exposición al regulador de crecimiento vegetal; pero a los cuatro meses en este último las muestras se fenolizaron. También se encontró que el tratamiento con $1 \mathrm{mg} / \mathrm{L}$ de 2, 4-D logró inducir la formación de callos a partir de brotes pequeños y grandes en $100 \%$ a los cuatro meses de exposición. Las hojas no respondieron a ningún tratamiento; mientras que los rizomas y raíces formaron callos en porcentajes menores a $40 \%$ de las muestras.

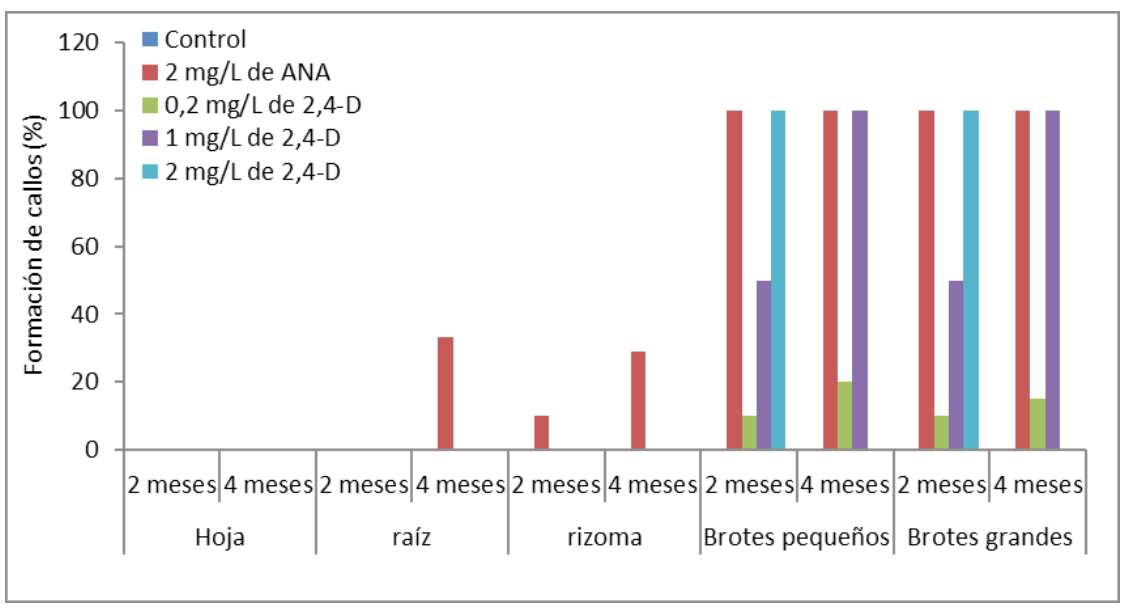

Figura 1. Formación de callos en Perezia coerulescens

En la figura 1 se muestra el porcentaje de callos formados en los diversos órganos a los dos y cuatro meses con y sin reguladores de crecimiento. Los valores corresponden 
a los promedios de los tratamientos con 20 repeticiones y las letras a los grupos con diferencia significativa luego de la prueba Duncan con $p<0,05$.

De acuerdo a los análisis estadísticos entre los tamaños de callos formados a partir de brotes pequeños a los dos y cuatro meses, se encontró que el mejor tratamiento fue 2 $\mathrm{mg} / \mathrm{L}$ de ANA como se observa en la figura 2A. Del mismo modo, para los tamaños de callos formados a partir de brotes grandes a los dos y a los cuatro meses muestra que el mejor tratamiento se obtuvo con $1 \mathrm{mg} / \mathrm{L}$ de 2,4-D de acuerdo a la figura $2 \mathrm{~B}$. Además, cuando se compararon los mejores tratamientos para el tamaño de callos en brotes pequeños y grandes se encontró que $2 \mathrm{mg} / \mathrm{L}$ de ANA en brotes pequeños indujo la formación de callos más grandes a 4 meses de exposición según figura 2C.
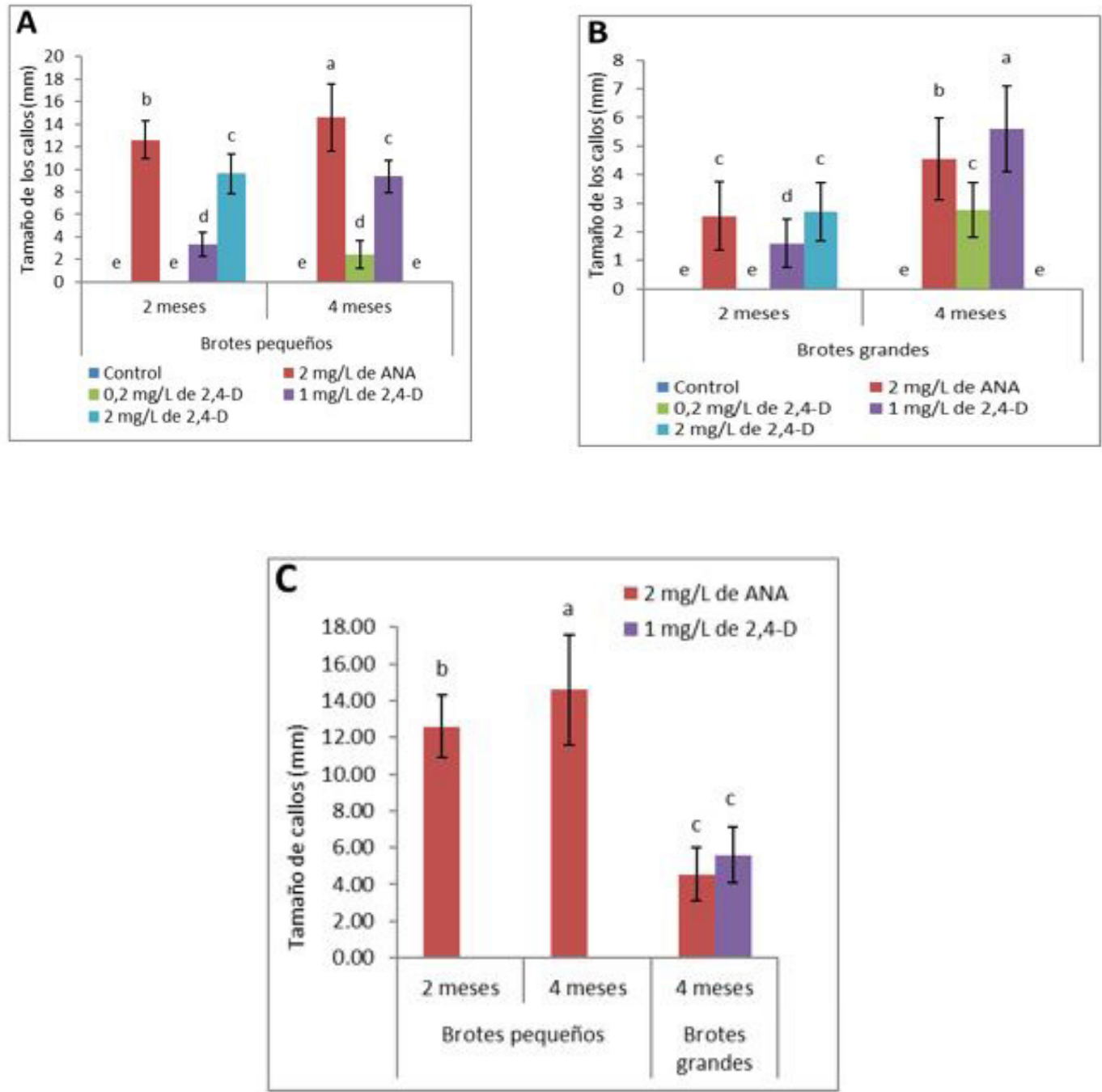

Figura 2. Tamaño de callos de Perezia coerulescens 
En la figura 2 se muestra el promedio del tamaño de los callos formados a partir de brotes pequeños (A), grandes (B) y entre los mejores tratamientos de A y B (C). Los valores corresponden a los promedios de 20 repeticiones y las letras a los grupos con diferencia significativa de acuerdo a la prueba Duncan con $\mathrm{p}<0,05$.

\section{Formación de embriones somáticos}

Respecto a los análisis estadísticos de los números de embriones somáticos germinados y formados a partir de los callos provenientes de brotes pequeños, se encontró que el mejor tratamiento fue $2 \mathrm{mg} / \mathrm{L}$ de ANA a los cuatro meses mostrado en la figura 3, y en el caso del número de embriones germinados a partir de callos formados de brotes grandes los tratamientos con $2 \mathrm{mg} / \mathrm{L}$ de ANA y $1 \mathrm{mg} / \mathrm{L}$ de 2,4-D a los cuatro meses no presentan diferencias estadísticas significativas luego de la prueba de Duncan como se muestra en la figura $3 \mathrm{~B}$.
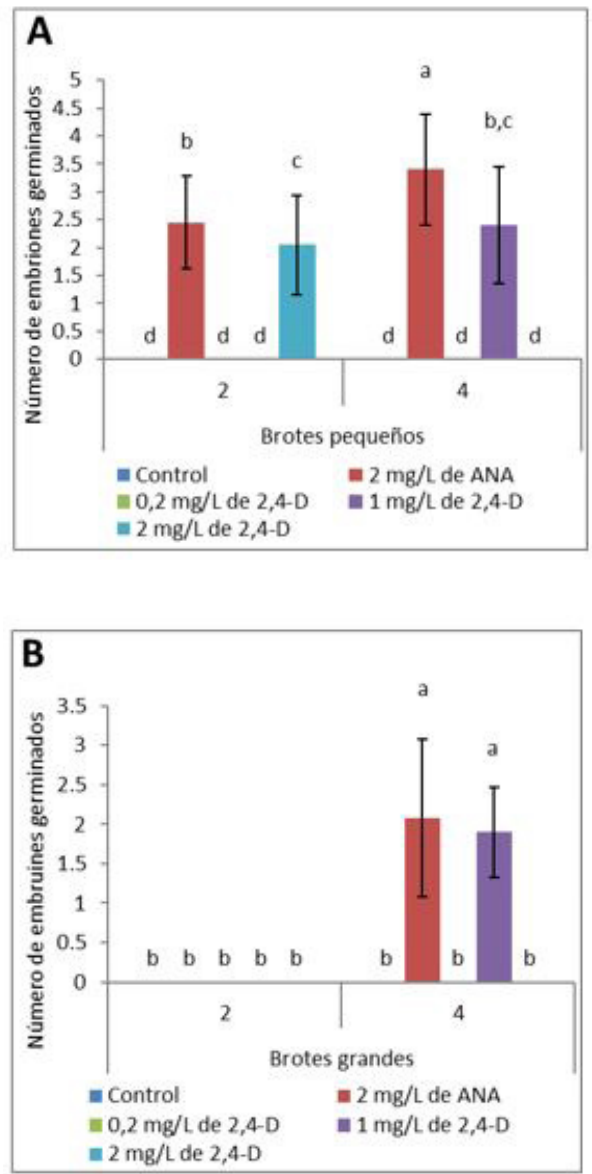

Figura 3. Número de embriones germinados de Perezia coerulescens 
En la figura 3 se muestra el promedio del número de embriones germinados obtenidos de los callos formados a partir de brotes pequeños (A) y grandes (B) a los dos y a los cuatro meses con y sin la adición de reguladores de crecimiento. Los valores corresponden a los promedios de 20 repeticiones y las letras a los grupos con diferencia significativa luego de realizar la prueba Duncan con $p<0,05$.

En la figura 4 se muestra la comparación entre los mejores tratamientos para el número de embriones germinados a partir de callos, donde se encontró que el mejor tratamiento fue $2 \mathrm{mg} / \mathrm{L}$ de ANA a los cuatro meses a partir de brotes pequeños.

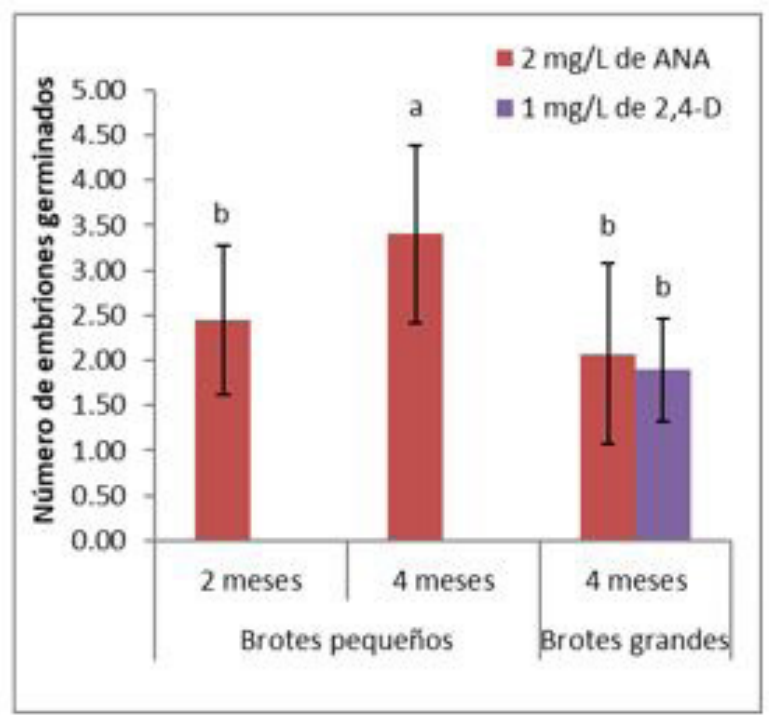

Figura 4. Embriones germinados en Perezia coerulescens

En la figura 4 se muestra el promedio del número de embriones germinados de los mejores tratamientos. Los valores corresponden a los promedios de 20 repeticiones y las letras a los grupos con diferencia significativa de acuerdo a la prueba Duncan con $p<0,05$.

\section{Etapas en la formación de los embriones somáticos}

La figura 5 muestra las diferentes etapas que conllevan a la formación de embriones somáticos de Perezia coerulescens en el tratamiento con ANA (2mg/L). 

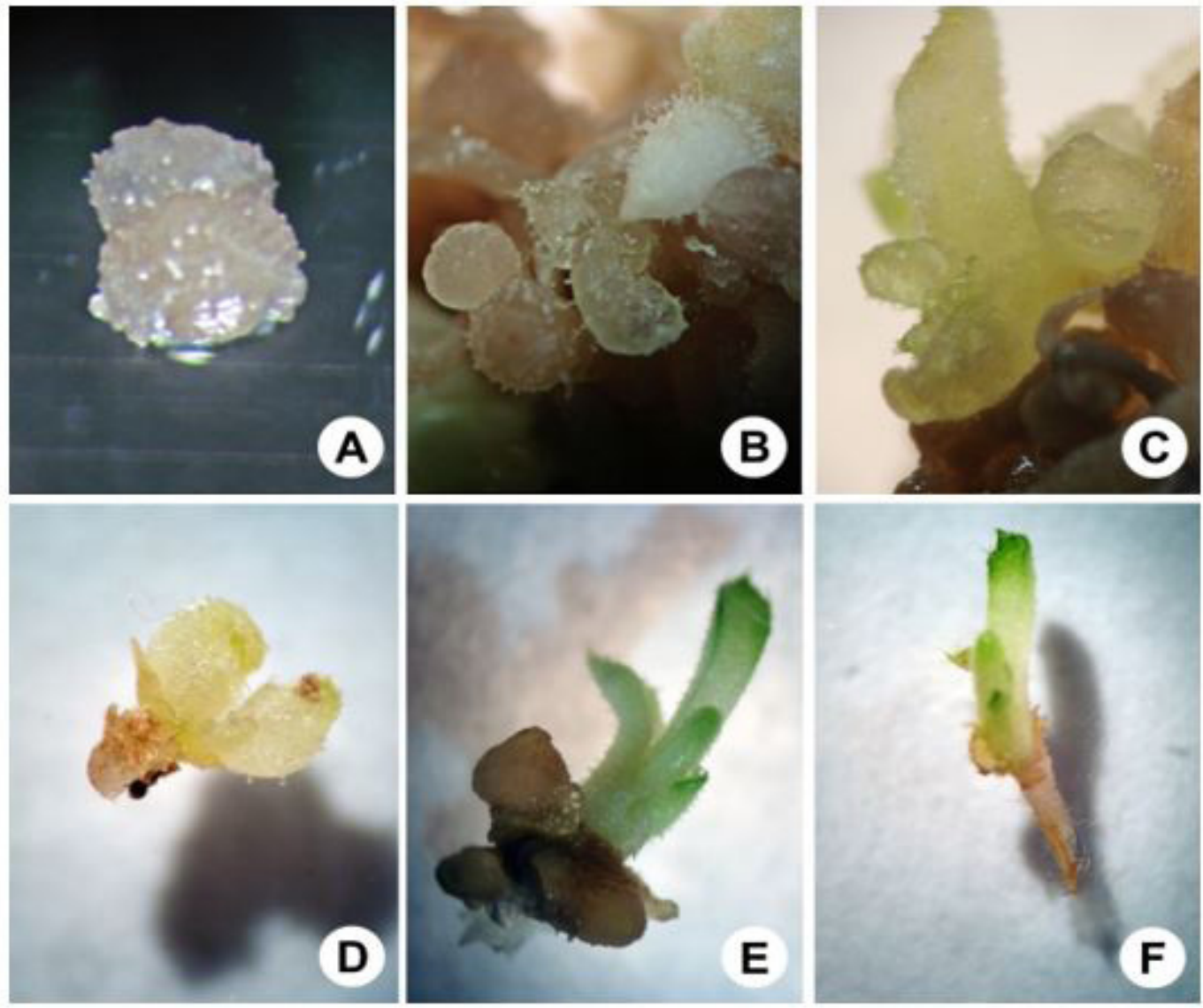

Figura 5. Fases de desarrollo de los embriones somáticos

(A) Fase de crecimiento indiferenciado, (B) Formación de embriones somáticos, (C) Formación del embrión, (D) Formación del embrión somático en la fase acorazonada, se observan los cotiledones, (E) Embrión somático en el que se observan los cotiledones y las hojas. (F) Plántula completa proveniente del embrión somático, se observa hojas y raíz.

\section{DISCUSIÓN}

La embriogénesis somática se caracteriza porque los embriones son obtenidos de células somáticas de tejidos provenientes de hojas, tallos, raíces y otros, que al ser sometidas a la acción de reguladores de crecimiento en cultivo pueden formar embriones (Freire, 2003; López, 1993). Es así, que se evaluó la capacidad de formar embriones somáticos usando hojas, raíces, rizomas y brotes grandes y pequeños de Perezia coerulescens, donde se encontró que las hojas no formaron callos en ningún tratamiento, mientras que los 
otros órganos formaron callos en los tratamientos con ANA (2mg/L) y 2,4-D (0,2 y 1 $\mathrm{mg} / \mathrm{L}$ ) de acuerdo a la figura 1 . Estos resultados estarían relacionados con la madurez del tejido usado; es así que pocas especies forman embriones somáticos a partir de tejidos de individuos adultos (Celestino et al., 2005), probablemente porque en estos tejidos las células tienen un mayor grado de diferenciación celular. Es decir, la formación de callos dependería de la edad del explante tal como refiere López (1993) quien ha encontrado que las hojas jóvenes producen callos en número mayor y de mejor calidad y Abdelnour y Vincent (1994) mencionan que los embriones cigóticos inmaduros son los explantes más favorables para la inducción de embriogénesis somática en la mayoría de los cereales. En concordancia, en Peręia coerulescens, se observó que la formación de callos se incrementa a medida que aumenta la probabilidad de la presencia de células menos diferenciadas o meristemáticas, en este caso los brotes produjeron la mayor cantidad de callos frente a los otros tejidos probablemente porque tienen mayor cantidad de tejidos meristemáticos.

La formación de callos es un proceso que depende de los reguladores de crecimiento y puede variar con el tiempo de exposición, por esta razón se aplicaron dos auxinas (ANA y 2, 4-D) y se evaluaron dos tiempos de exposición; encontrándose que ANA indujo la formación de callos en la mayoría de tejidos frente a 2, 4-D que sólo tuvo efectos sobre los brotes como se muestra en la figura 1. Así mismo, los callos provenientes de los brotes fueron visibles a partir de los dos meses; concordando con los resultados obtenidos por Olivera-Gonzales et al. (2017) quienes encontraron ligera formación de callos en Perezia pinnatifida con ANA 1 y $2 \mathrm{mg} / \mathrm{L}$. En el caso de los tratamientos con 2, 4-D, ambas concentraciones $(0,2 \mathrm{mg} / \mathrm{L}$ y $2 \mathrm{mg} / \mathrm{L})$ indujeron la formación de callos a los dos meses en los dos tipos de brotes. Este efecto se incrementó a los cuatro meses sólo para la concentración menor, contrariamente los callos del tratamiento con $2 \mathrm{mg} / \mathrm{L}$ se fenolizaron, dejando en evidencia que la concentración y tiempo de exposición a este regulador de crecimiento afectan la sobrevivencia del explante y la formación de callos. Así mismo, la concentración del regulador de crecimiento vegetal y el tiempo de exposición es variable de acuerdo a la especie, por ejemplo, Vílchez (2002) obtuvo la formación de callos compactos en Psidium guajava en $1 \mathrm{mg} / \mathrm{L}$ de 2, 4-D a dos semanas de exposición, manifestando que a concentraciones mayores el tiempo requerido para la formación del callo demoraba hasta tres semanas. En los tratamientos aplicados se encontró que ANA $(2 \mathrm{mg} / \mathrm{L})$ tuvo mejor efecto en la inducción de formación de callos frente al 2, 4-D de acuerdo a la figura 2, a pesar que la mayoría de metodologías utilizan esta última para este proceso. Sin embargo, otros reguladores pueden mostrar efectos similares por ejemplo Jiménez y Guevara (1995) obtuvieron callos entre 7 y 10 meses a partir de embriones inmaduros de naranja dulce (Citrus sinensis) y naranja agria (C. aurantium) en presencia de BAP a la concentración de 
$10 \mathrm{mg} / \mathrm{L}$; así mismo Karina et al. (2002) obtuvo callos en variedades de caña de azúcar a partir de los 45 días en medios que contenían 30 $\mu \mathrm{M}$ de Dicamba. Por otro lado, durante la formación de callos pueden intervenir algunos factores externos como el fotoperiodo, temperatura y $\mathrm{pH}$ del medio; por ejemplo en muchos casos que la inducción de callos puede darse en oscuridad (Karina et al., 2002; Vílchez, 2002; Alarcón et al., 2006), a fotoperiodos de 16 horas de luz (Martínez et al., 2004; Manzanera, 1992; Espinoza et al., 1992), a fotoperiodos de 24 horas de luz (Jiménez y Guevara, 1995). En el caso de Pereqia coerulescens se obtuvieron los callos a 16 horas luz; sin embargo, podrían evaluarse otros fotoperiodos para optimizar el proceso.

Las citoquininas en ocasiones son utilizadas para inducir la embriogénesis somática especialmente en la etapa de maduración del embrión somático (Abdelnour y Vincent, 1994). Por ejemplo, Rivero et al. (2008) utilizaron 6-BAP a una concentración de $1,78 \mu \mathrm{M}$ para la germinación de los callos, así mismo Martínez et al. (2004) obtuvieron porcentajes de germinación de $2-50 \%$ de embriones somáticos a partir de callos de mandioca (Manihot esculenta) tratados con 0,1 mg/L de BA y 0,01 mg/L de 2,4-D, Gholami et al. (2013) encontraron que la maduración de los embriones de citrus está ligada a altas concentraciones de sacarosa $(50 \mathrm{~g} / \mathrm{L})$ y a la adición de BAP, y Fernández-Guijarro et al. (1995) encontraron que Quercus suber al inicio de la formación de embriones somáticos requiere dosis altas de benciladenina y ANA seguido de la disminución de la dosis y el traspaso a medio sin reguladores de crecimiento. En el caso de Perezia coerulescens, se consiguió la germinación de los embriones somáticos sin la adición de reguladores de crecimiento diferentes al ANA observados en las figuras 4, 5E y 5F. Sin embargo, Olivera-Gonzales et al. (2017) encontraron que BAP a 0,5 mg/L posterior a tres meses de cultivo del callo sin regulador de crecimiento permite una mayor regeneración de embriones en $P$. pinnatifida, además que concentraciones mayores a $0,5 \mathrm{mg} / \mathrm{L}$ de BAP y la combinación de citoquininas y auxinas reducen la germinación de los embriones somáticos. Lo cual sugiere que pueden realizarse investigaciones posteriores para optimizar la regeneración de embriones.

\section{CONCLUSIONES}

Se logró la formación de callos a partir de raíces, rizomas, y brotes pequeños y grandes con el tratamiento de $2 \mathrm{mg} / \mathrm{L}$ de ANA a cuatro meses de exposición; mientras que solo los brotes pequeños y grandes formaron callos con los tratamientos con 2, 4-D.

Los callos de mayor tamaño y el mayor número de embriones somáticos germinados se han obtenido a partir de brotes pequeños cultivados con $2 \mathrm{mg} / \mathrm{L}$ de ANA por cuatro meses. 


\section{REFERENCIAS BIBLIOGRÁFICAS}

Abdelnour, A. y Vincent, J. 1994. Conceptos básicos del cultivo de tejidos vegetales. Costa Rica: CATIE. Turrialba.

Abdi, G. y Hedayat, M. 2011. «Induction of somatic embryogenesis from immature zygotic embryo and immature seed of royal Poinciana (Delonix regia)». World Applied Science Journal, Vol. 13, N 3: 391-395.

Alarcón, J. et al. 2006. «Evaluación de algunas combinaciones de reguladores de crecimiento inductoras de callos en achiote (Bixa orellana L.), planta activa contra la mordedura de serpientes». VTTAE, Revista de la Facultad de Química Farmacéntica Vol. 13, N 1: Colombia: Universidad de Antioquia, Medellín. 17-23.

Brunetti, P. et al. 2007. «Micropropagación de "Tomillo de las Sierras" Hedeoma multiflorum Benth». Bol. Latinoam. Caribe Plant. Med. Aromáticas Vol. 6, N 6. México: Universidad Autónoma del Estado de México. 391 - 392.

Celestino, C. et al. 2005. «La embriogénesis somática como elemento central de la biotecnología forestal». Invest Agrar: Sist Recur For. Vol 14; N 3: 345 - 357.

EL PERUANO: Diario Oficial. 2006. Normas Legales: Aprueban categorización de Especies amenazadas de flora silvestre, Decreto Supremo No 043-2006-AG. Lima: Empresa Peruana de Servicios Editoriales S.A. Domingo, 17 de setiembre. pp. 323527 323539 .

Fernández-Guijarro, B. 1995. «Influence of external factors on secondary embryogenesis and germination in somatic embryos from leaves of Quercus subens. Plant Cell, llssue and Organ Culture. N41. Netherland. 99-106.

Freire, Marisol. 2003. «Aspectos básicos de la embriogénesis somática». Biotecnología Vegetal. Vol. 3, $\mathrm{N}^{\circ}$ 4: 195 - 209.

Gholami, Alam et al. 2013. «Plant regeneration through direct and indirect somatic embryogenesis from immature seeds of citrus». European Journal of Experimental Biology. Vol. 3, No 3: $307-310$.

Jiménez, V. y Guevara, E. 1995. «Regeneración in vitro mediante embriogénesis somática de variedades de cítricos. I. Obtención de callo friable y suspensiones celulares de naranja dulce (Citrus sinensis) y naranja agria (Citrus aurantium) cultivadas en Costa Rica». Agronomía Costarricense. Vol. 19, N² 2. Costa Rica. 7 - 18.

Karina, A. et al. 2002. «Optimización del proceso de embriogénesis somática en variedades venezolanas de caña de azucar». Acta Cientifica Venezolana. Vol. 53, N 4. Venezuela 251-257.

Kumar, S. et al. 2016. «Influence of nutrient media on callus induction, somatic embryogenesis and plant regeneration in selected Turkish crocus species». Biotechnology Reports. Vol. 10: 66-74.

López, Gerardo. 1993. «Producción de callos de Catharanthus roseus (L) G. Don in vitro». Ciencias Agrícolas. Vol. 12: 46 - 65.

Manzanera, J. 1992. «Inducción de embriogénesis somática en roble (Quercus robur L.)». Invest. Agrar., Sist. Recur. For. Vol. 1, N 1: $73-81$. 
Martínez, R. et al. 2004. «Embriogénesis somática de Eucalyptus grandis Hill ex Maiden y Eucalyptus urophyllas S. T. Blake». Revista Chapingo. Serie ciencias forestales y del ambiente. Vol 10, N² 2. México: Universidad Autónoma Chapingo. 83-92.

Olivera-Gonzales, Percy; Espinoza, Rosa y Tamariz-Angeles, Carmen.2017. «Multiplicación in vitro y embriogénesis somática de Perezia pinnatifida (Asteraceae) planta medicinal andina». Revista peruana de biología Vol. 24, N 3. Lima: Facultad de Ciencias Biológicas UNMSM. 323 - 328.

Ortíz, L. et al. 2007. «Regeneración in vitro de plantas de poleo (Lippia turbinata Griseb var turbinata)». Bol. Latinoam. Caribe Plant. Med. Aromáticas: Vol. 6, N 6: 403 - 404.

Peddaboina, V. et al. 2016. «Somatic embryogenesis and plant regeneration of Capsicum baccatum L». Journal of Genetic Engineering and Biotechnology. Vol. 14, N 1: 55-60.

Rivero, N. et al. 2008. «Embriogénesis somática en (Anthurium andreanum Lind.) variedad Lambada». Ra Ximhai: Revista de sociedad, cultura y desarrollo sustentable. México: Universidad Autónoma Indígena de México. 135 - 149.

Rodríguez, D. et al. 2015. «Embriogénesis somatica en el cultivar de platano "FHIA25” (AAB) a partir de ápices meristemáticos». Revista Colombiana de Biotecnología. Vol 17, N². Colombia: Universidad Nacional de Colombia. 65 -75.

Shekhawat, S. y Manokari, M. 2016. «Somatic embryogenesis and in vitro flowering in Hybanthus enneaspermus (L.) F. Muell. - A rare multipotent herb». Asian Pacific Journal of Reproduction. Vol. 5, $\mathrm{N}^{\circ}$ 3. India. 256-262.

Silveira, V. et al. 2013. «Morphological and polyamine content changes in embryogenic and non-embryogenic callus of sugarcane». Plant Cell, Tissue and Organ Culture. Vol. 114, $\mathrm{N}^{\circ}$ 3: 351-364.

Taiz, L. y Zeiger, E. 2010. Plant Physiology. Fifth edition. U.S.A: Edit. Sinauer Associates.

Thomas, C. y Jiménez, V. 2005. Mode of action of plant hormones and plant growth regulators during induction of somatic embryogenesis: molecular aspects. In: MUJIB, A. and SAMAJ, J. eds. Somatic Embryogenesis, Plant Cell Monographs. Berlin; Springer-Verlag.

Vieira, E. L. et al. 2010. Manual de Fisiologia vegetal. Sao Luis: EDUFMA.

Vílchez, J. et al. 2002. «Inducción de embriogénesis somática en Psidium guajava L. a partir de embriones cigóticos». Rev. Fac. Agrom. (LUZ). Vol. 19. Venezuela: Universidad del Zulia. 284 - 293.

Von Arnold, S. 2008. Somatic embryogenesis. In: George, E. F., Hall, M.A. and de Klerk, G-J (eds). Plant propagation by tissue culture. 3 ed. The Netherlands: Springer.

Recepción: 17/09/2018

Aceptación: 20/11/2018

\section{Correspondencia}

Percy Olivera-Gonzales

poliverag@unasam.edu.pe 